\title{
Neck circumference: an easier measure to identify excess weight and cardiovascular risk?
}

Keywords: neck circumference, BMI; CVD, chronic disease, metabolic syndrome

Abbreviations: BMI, body mass index; CVD, cardiovascular disease; MS, metabolic syndrome; WC, waist circumference; NC, neck circumference

\section{Commentary}

Obesity is a complex and chronic disease, associated with several comorbidities and has achieved epidemic proportions worldwide. It's diagnose is easily achieved by the calculation of the body mass index (BMI) using a formula that divides body weight in kilograms by squared height in meters. However, the BMI does not differentiate excessive adipose tissue from lean body mass, nor subcutaneous from visceral fat. Meanwhile, numerous techniques to assess weight related parameters are available, ${ }^{1}$ from anthropometrics to sophisticated computer tomography and dual-energy X-ray absorptiometry, but none are at the same time precise, cheap and feasible for use in clinical practice.

The metabolic syndrome (MS) has long been considered a risk factor for cardiovascular disease (CVD). Several organizations have established different criteria to diagnose this condition, all of them using the waist circumference (WC) as a reflection of central obesity, associated with the development of both MS and CVD in the long term. However, the measurement of WC is not easy, particularly in some individuals with excess weight in the abdominal area and cut-off values for WC are object of debate. Other indices, such as waist-to-hip and waist-to-height ratio have been proposed, but are not currently adopted worldwide.

Neck circumference (NC) measurement arises as an interesting tool to address the concerns mentioned before. $\mathrm{NC}$ is an anthropometric measure of obesity which reflects fat deposition in the upper body. Association of NC with MS and its components, insulin resistance, fatty liver disease, sleep apnea and biomarkers of inflammation have been previously reported. . $^{-11}$ Interestingly, new studies have demonstrated an association between $\mathrm{NC}$ and indicators of atherosclerosis, as carotid intimal-media thickness, but not coronary artery calcium. ${ }^{12}$ A recent study suggested that increased $\mathrm{NC}$ might even predict fatal and non-fatal cardiovascular events. ${ }^{13}$

It seems clear that $\mathrm{NC}$ should be considered a novel marker for CVD. However, there is no universal cut-off for NC up to now. Large studies are needed to provide adequate cut-off values for different populations and ethnicities. Even though, it is my opinion that neck circumference assessment is both time- and cost-saving strategy to screen for individuals at excess weight from a public health perspective. So, yes, neck circumference is an easily obtained measurement of excess weight, cheap and feasible, which also identifies patients at higher cardiovascular risk.

\section{Acknowledgements}

None.

\author{
Volume 4 Issue 5 - 2017 \\ Marilia Izar Helfenstein Fonseca
University of Sao Paulo, Brazil \\ Correspondence: Marilia Izar Helfenstein Fonseca, School \\ of Public Health, University of Sao Paulo, Sao Paulo, Brazil,Tel \\ +551|98196458I,Email marilia fonseca@yahoo.com.br
}

Received: May 05, 2017 | Published: May II, 2017

\section{Conflicts of interest}

The author declares there is no conflict of interest.

\section{References}

1. Rezende F, Rosado L, Franceschinni S, et al. Critical revision of the available methods for evaluate the body composition in population-based and clinical studies. Arch Latinoam Nutr. 2007;57(4):327-334.

2. Ben Noun L, Sohar E, Laor A. Neck circumference as a simple screening measure for identifying overweight and obese patients. Obes Res. 2000;9(8):470-477.

3. Ben Noun L, Laor A. Relationship of neck circumference to cardiovascular risk factors. Obes Res. 2003;11(2):226-231.

4. Preis SR, Massaro JM, Hoffmann U, et al. Neck circumference as a novel measure of cardiometabolic risk: the Framingham Heart study. J Clin Endocrinol Metab. 2010;95(8):3701-3710.

5. Kurtoglu S, Hatipoglu N, Mazicioglu MM, et al. Neck circumference as a novel parameter to determine metabolic risk factors in obese children. Eur J Clin Invest. 2012;42(6):623-630.

6. Zhou JY, Ge H, Zou MF, et al. Neck circumference as an independent contributor to cardio-metabolic syndrome. Cardiovasc Diabetol. 2013;12:76

7. Stabe C, Vasques ACJ, Lima MMO, et al. Neck circumference as a simple tool for identifying the metabolic syndrome and insulin resistance: results from the Brazilian Metabolic Syndrome Study. Clin Endocrinol (Oxf). 2013;78(6):874-881.

8. da Silva Cde C, Zambon MP, Vasques AC, et al. Neck circumference as a new anthropometric indicator for prediction of insulin resistance and components of metabolic syndrome in adolescents: Brazilian Metabolic Syndrome Study. Rev Paul Pediatr. 2014;32(2):221-229.

9. Baena CP, Lotuffo PA, Fonseca MG, et al. Neck circumference is independently associated with cardiometabolic risk factors: crosssectional analysis from ELSA-Brasil. Metab Syndr Relat Disord. 2016;14(3):145-153.

10. Vallianou NG, Evangelopoulos AA, Bountziouka V, et al. Neck circumference is correlated with triglycerides and inversely related with HDL cholesterol beyond BMI and waist circumference. Diabetes Metab Res Rev. 2013;29(1):90-97. 
11. Huang BX, Zhu MF, Wu T, et al. Neck circumference, along with other anthropometric indices, has an independent and additional contribution in predicting fatty liver disease. PLoS One. 2015;10(2):0118071e.

12. Baena CP, Lotuffo PA, Santos IS, et al. Neck circumference is associated with carotid intimal-media thickness but not with coronary artery calcium: results from the ELSA-Brasil. Nutr Metab Cardiovasc Dis. 2016;26(3):216-222.
13. Dai Y, Wan X, Li X, et al. Neck circumference and future cardiovascular events in a high-risk population-A prospective cohort study. Lipids Health Dis. 2016;15:46. 